\title{
A FAST MODE SELECTION ALGORITHM IN H.264 VIDEO CODING
}

\author{
Donghyung Kim and Jechang Jeong \\ Dept. of Electrical and Computer Engineering \\ Hanyang University \\ Haengdang, Seongdong, Seoul, South Korea
}

\begin{abstract}
For improvement of coding efficiency, the H.264 video coding standard uses new coding tools, such as variable block size, quarter-pixel-accuracy motion estimation, multiple reference frames, intra prediction, loop filter, etc. Using these coding tools, H.264 achieves significant improvement in coding efficiency compared with existing standards. However, encoder complexity increases tremendously. Among the tools, the macroblock mode selection and the motion estimation contribute most to total encoder complexity. This paper focuses on complexity reduction in macroblock mode selection. Of all macroblock modes which can be selected, inter $8 \times 8$ and intra $4 \times 4$ have the highest complexity. We propose two methods for complexity reduction of inter $8 \times 8$ and intra $4 \times 4$ by using the costs of the other macroblock modes. Simulation results show that the proposed methods save up to $57.7 \%$ of total encoding time compared with the H.264 reference implementation, whereas the average PSNR only decreases less than $0.05 \mathrm{~dB}$.
\end{abstract}

\section{INTRODUCTION}

For improvement of coding efficiency, H.264 adopts new coding tools, such as quarter-pixel-accuracy motion estimation (ME), multiple reference frames, loop filter, variable block size (VBS), etc. [1-3]. These tools have enabled the standard to achieve higher coding efficiency than prior video coding standards. The encoder complexity, however, increases tremendously.

Several approaches have been proposed to reduce the H.264 encoder complexity. Yin et al. proposed a method to alleviate the encoder complexity caused by $\mathrm{ME}$ and macroblock mode selection [4]. Their low complexity ME algorithm consists of two steps. First, integer-pixel ME is carried out using enhanced prediction zonal search (EPZS). Then, depending on the result of the integer-pixel ME, subpixel ME is carried out within some limited areas. For faster macroblock mode selection their method simply examines limited modes based on the costs of inter $16 \times 16$, inter $8 \times 8$, and inter $4 \times 4$. Huang et al. proposed an algorithm to reduce the time to search the reference frames for ME complexity

This work was supported in part by the Human Resource Development Project for IT SoC Key Architect under Korea IT Industry Promotion Agency. reduction [5]. For each macroblock, they analyze the available information after intra prediction and $\mathrm{ME}$ from the previous frame to determine whether it is necessary to search more frames. Their method can save about $10-67 \%$ of ME computation. Ahmad et al. proposed a fast algorithm for macroblock mode selection based on a $3 \mathrm{D}$ recursive search algorithm that takes into account the cost and the previous frame information [6]. This algorithm leads to over $30 \%$ decrease in encoding time compared with the H.264 reference implementation. The bitstream length, however, increases by about $15 \%$.

To speed up the H.264 encoding time, we focus on complexity reduction of the macroblock mode selection. When $8 \times 8$ DCT is not used, the candidate macroblock modes are SKIP, inter $16 \times 16$, inter $16 \times 8$, inter $8 \times 16$, inter $8 \times 8$, intra $16 \times 16$, and intra $4 \times 4$. An inter $8 \times 8$ mode can be further partitioned into four sub-macroblock modes: inter $8 \times 8$, inter $8 \times 4$, inter $4 \times 8$, and inter $4 \times 4$. Among these modes, inter $8 \times 8$ and intra $4 \times 4$ modes contribute most to the complexity, especially when rate-distortion optimization (RDO) is used.

In this paper, we propose two algorithms. One is to alleviate inter $8 \times 8$ complexity. It estimates four submacroblock modes within inter $8 \times 8$ by using the costs of other inter modes with relatively low complexity. The other method reduces intra $4 \times 4$ complexity, using similarity between the RD costs of two intra modes.

\section{MODE SELECTION ALGORITHM IN THE H.264 REFERENCE SOFTWARE}

\subsection{Macroblock and Sub-macroblock Modes}

The H.264 standard allows the following macroblock modes: SKIP, inter $16 \times 16$, inter $16 \times 8$, inter $8 \times 16$, inter $8 \times 8$, intra $16 \times 16$, intra $8 \times 8$, and intra $4 \times 4$. Furthermore, each block within inter8x 8 can be divided into four sub-macroblock modes. The allowed sub-macroblock modes are inter $8 \times 8$, inter $8 \times 4$, inter $4 \times 8$, and inter $4 \times 4$. Fig. 1 depicts the macroblock partitions of inter and intra macroblock modes including SKIP mode.

An inter $16 \times 16$ mode has only one motion vector, whereas inter $16 \times 8$ and inter $8 \times 16$ have two motion vectors. An inter $8 \times 8$ mode may have $4-16$ motion vectors depending on the selected sub-macroblock modes. A SKIP mode refers to the mode where neither motion vector nor residual is encoded. Three intra modes have different prediction modes. 

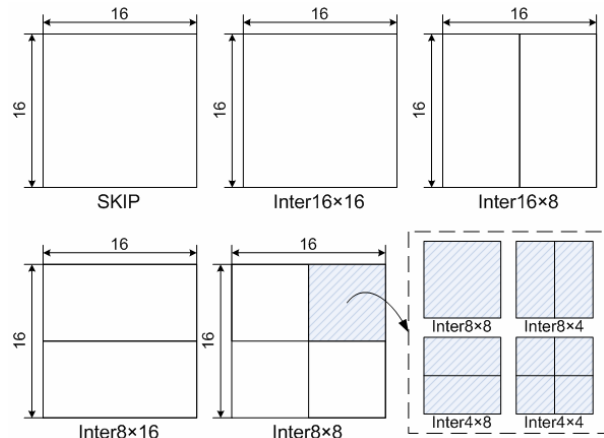

(a)
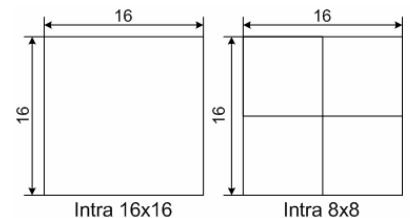

(b)

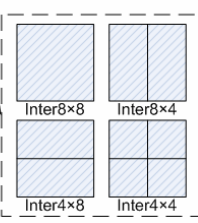

Figure 1. Macroblock partitions of inter(a) and intra(b) modes

Four prediction modes are available in intra $16 \times 16$, and nine prediction modes in intra8 88 and intra $4 \times 4$.

\subsection{Macroblock Mode Selection in Joint Model (JM)}

The reference software, JM9.3 [7], supports three cost calculation criteria: motion vector (MV) cost, reference frame (REF) cost, and rate distortion (RD) cost. The MV cost is calculated by using a lambda factor defined as:

$$
\begin{aligned}
& \begin{array}{l}
\text { MVcost }=\text { WeightedCost }(\text {, mvbits }[(c x<<s)-p x] \\
\qquad+m v b i t s[(c y<<s)-p y])
\end{array} \\
& \text { where, } \\
& f \text { : lambda factor } \\
& c x, \text { cy: candidate } x \text { and y position for } M E \\
& \text { px, py: predicted } x \text { and } y \text { position for } M E
\end{aligned}
$$

The REF cost is also calculated by using a lambda factor defined as:

$$
\begin{aligned}
& \text { REFcost }=\text { WeightedCost }(\text {, refbits }(\text { ref })) \\
& \text { where, } f: \text { lambda factor }
\end{aligned}
$$

In (1) and (2), WeightedCost ( ) returns the cost for the bits of motion vector and reference frame, respectively. Finally, the RD cost is defined as:

$$
\begin{aligned}
& \mathrm{RDcost}=\text { Distortion }+\lambda \cdot \text { Rate } \\
& \text { where, } \lambda: \text { Lagrange multiplier }
\end{aligned}
$$

In (3), the distortion is computed by calculating the SNR of the block and the rate is calculated by taking into consideration the length of the stream after the last stage of encoding.

When RDO and five reference frames are used, using these cost functions, the process of macroblock mode selection in the reference software is as follows:
Step 1 Find reference frames and motion vectors for each block in inter $16 \times 16$, inter $16 \times 8$, and inter $8 \times 16$.

$$
\begin{aligned}
& {\left[\mathbf{M V}_{i}, \mathbf{R E F}_{i}\right]=\underset{M V, R E F}{\arg \min }(\mathrm{MV} \operatorname{cost}(M V)+\mathrm{REF} \operatorname{cost}(R E F))} \\
& \text { where, } i=\text { inter } 16 \times 16, \text { inter } 16 \times 8, \text { inter } 8 \times 16 . \\
& M V \in\{\text { Search Range }\}, R E F \in\{0,1, \cdots, 4\} \\
& \mathbf{M V}_{i}: \text { Motion vector set in } i \text { mode } \\
& \mathbf{R E F}_{i}: \text { Reference frame set in } i \text { mode }
\end{aligned}
$$

Step 2 Calculate the sums of MV cost and REF cost in inter $16 \times 16$, inter $16 \times 8$, and inter $8 \times 16$.

$$
\begin{aligned}
& J_{i}=\mathrm{MV} \operatorname{cost}\left(\mathbf{M V}_{i}\right)+\mathrm{REF} \operatorname{cost}\left(\mathbf{R E F}_{i}\right) \\
& \text { where, } i=\text { inter } 16 \times 16, \text { inter } 16 \times 8, \text { inter } 8 \times 16 . \\
& J_{i}: \text { the sum of } \mathrm{MV} \text { cost and } \mathrm{REF} \text { cost in i mode. }
\end{aligned}
$$

Step 3 Find reference frames and motion vectors for the $1^{\text {st }}$ sub-macroblock in inter $8 \times 8$.

$$
\begin{aligned}
& {\left[\mathbf{M V}_{i}, \mathbf{R E F}_{i}\right]=\underset{M V, R E F}{\arg \min }(\mathrm{MV} \operatorname{cost}(M V)+\operatorname{REF} \operatorname{cost}(R E F))} \\
& \text { where, } i=\text { inter } 8 \times 8, \text { inter } 8 \times 4, \text { inter } 4 \times 8, \text { inter } 4 \times 4 .
\end{aligned}
$$

Step 4 Calculate the sums of MV cost and REF cost for the $1^{\text {st }}$ sub-macroblock in inter $8 \times 8$.

$$
\begin{aligned}
& J_{i}=\mathrm{MV} \operatorname{cost}\left(\mathbf{M V}_{i}\right)+\operatorname{REF} \operatorname{cost}\left(\mathbf{R E F} \mathbf{F}_{i}\right) \\
& \text { where, } i=\text { inter } 8 \times 8, \text { inter } 8 \times 4, \text { inter } 4 \times 8, \text { inter } 4 \times 4 .
\end{aligned}
$$

Step 5 Select the mode for the $1^{\text {st }}$ sub-macroblock in inter $8 \times 8$.

$$
\begin{aligned}
& \text { Sub-macroblock mode }= \\
& \underset{\text { mode }}{\operatorname{argmin}}(\mathrm{RDcost}(\text { inter } 8 \times 8), \mathrm{RDcost}(\text { inter } 8 \times 4) \\
& \quad, \mathrm{RDcost}(\text { inter } 4 \times 8), \mathrm{RDcost}(\text { inter } 4 \times 4))
\end{aligned}
$$

Step 6 Repeat Steps 3 to 5 for the other sub-macroblocks in inter $8 \times 8$.

Step 7 Select the macroblock mode

$$
\begin{aligned}
& \underset{\text { Macroblock mode }}{\operatorname{argmin}}(\mathrm{RDcost}(S K I P), \mathrm{RDcost}(\text { inter } 16 \times 16) \\
& , \mathrm{RDcost}(\text { inter } 16 \times 8), \mathrm{RDcost}(\text { inter } 8 \times 16), \mathrm{RDcost}(\text { inter } 8 \times 8) \\
& , \mathrm{RDcost}(\text { intra } 16 \times 16), \mathrm{RD} \operatorname{cost}(\text { intra } 4 \times 4))
\end{aligned}
$$

In Step 1 and Step 2, the reference software finds reference frames and motion vectors which minimize the sum of MV cost and REF cost in inter $16 \times 16$, inter $16 \times 8$, and inter $8 \times 16$. Steps 3 to 6 are the process to select submacroblock modes in inter $8 \times 8$. The final step decides the macroblock mode by comparing RD costs of all macroblock modes.

\section{PROPOSED ALGORITHM}

\subsection{Complexity Reduction of Inter $8 \times 8$}

Since each sub-macroblock within inter $8 \times 8$, for the selection of sub-macroblock modes, needs additional RD cost computations, inter $8 \times 8$ has the highest complexity among all inter macroblock modes. For complexity 


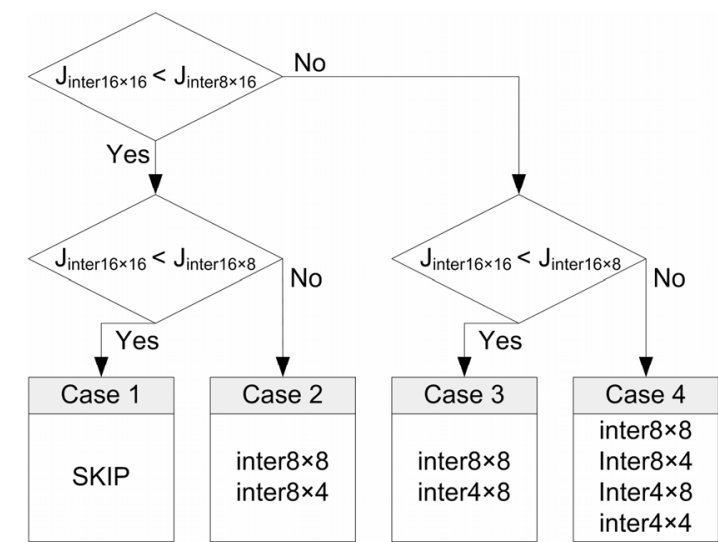

Figure 2. Restriction of selectable sub-macroblock modes.

reduction of inter $8 \times 8$ we assume that the costs of inter macroblock modes monotonically increase or decrease according to partitioned direction. Using this assumption, we restrict selectable sub-macroblock modes by using the MV costs and REF costs of inter $16 \times 16$, inter $16 \times 8$, and inter $8 \times 16$. For example, if the sum of MV and REF costs of inter $16 \times 16$ is larger than that of inter $16 \times 8$ and is smaller than that of inter $8 \times 16$, we only consider inter $8 \times 8$ and $8 \times 4$ as sub-macroblock modes. Fig. 2 depicts the proposed method for the complexity reduction of inter $8 \times 8$.

In case 1 , since $\mathrm{J}_{\text {inter } 16 \times 16}$ is smaller than both $\mathrm{J}_{\text {inter } 16 \times 8}$ and $\mathrm{J}_{\text {inter } 8 \times 16}$, neither additional block partition in horizontal direction nor in vertical direction is needed. In this case, we do not consider any sub-macroblock mode, and the process of Step 3 to Step 6 in the reference software is skipped. In case 2 , since $\mathrm{J}_{\text {inter16 } \times 16}$ is smaller than $\mathrm{J}_{\text {inter } 8 \times 16}$ and is larger than $\mathrm{J}_{\text {inter16 }} \times 8$, additional block partition is only considered in the vertical direction. In this case, either inter $8 \times 8$ and inter $8 \times 4$ is selected as a sub-macroblock mode, and the formulae of Steps 3 to 6 in the reference software are modified as follows:

$$
\begin{aligned}
& {\left[\mathbf{M V}_{i}, \mathbf{R E F}_{i}\right]=\underset{M V, R E F}{\arg \min }(\mathrm{MV} \operatorname{cost}(M V)+\mathrm{REF} \operatorname{cost}(R E F))} \\
& \text { where, } i=\text { inter } 8 \times 8, \text { inter } 4 \times 8 . \\
& J_{i}=\mathrm{MV} \operatorname{cost}\left(\mathbf{M V}_{i}\right)+\mathrm{REF} \operatorname{cost}\left(\mathbf{R E F}_{i}\right) \\
& \text { where, } i=\text { inter } 8 \times 8, \text { inter } 8 \times 4 . \\
& \text { Sub }- \text { macroblock mode }= \\
& \quad \underset{\text { mode }}{\operatorname{argmin}}(\mathrm{RDcost}(\text { inter } 8 \times 8), \operatorname{RDcost}(\text { inter } 8 \times 4))
\end{aligned}
$$

In case 3 , since $\mathrm{J}_{\text {inter16 } \times 16}$ is smaller than $\mathrm{J}_{\text {inter16 } \times 8}$ and is larger than $\mathrm{J}_{\text {inter } 8 \times 16}$, only additional block partition only in the horizontal direction is considered. In this case, either inter $8 \times 8$ and inter $4 \times 8$ is selected as a sub-macroblock mode, and the formulae of Steps 3 to 6 in the reference software are modified as follows:

$$
\begin{aligned}
& {\left[\mathbf{M V}_{i}, \mathbf{R E F}_{i}\right]=\underset{M V, R E F}{\arg \min }(\mathrm{MV} \operatorname{cost}(M V)+\mathrm{REF} \operatorname{cost}(R E F))} \\
& \text { where, } i=\text { inter } 8 \times 8 \text {, inter } 4 \times 8 . \\
& \qquad J_{i}=\mathrm{MV} \operatorname{cost}\left(\mathbf{M V} \mathbf{V}_{i}\right)+\mathrm{REF} \operatorname{cost}\left(\mathbf{R E F}_{i}\right) \\
& \quad \text { where, } i=\text { inter } 8 \times 8, \text { inter } 4 \times 8 .
\end{aligned}
$$

$$
\begin{aligned}
& \text { Sub }- \text { macroblock mode }= \\
& \underset{\text { mode }}{\operatorname{argmin}}(\operatorname{RDcost}(\text { inter } 8 \times 8), \operatorname{RDcost}(\text { inter } 4 \times 8))
\end{aligned}
$$

In case 4 , since $\mathrm{J}_{\text {inter16 } \times 16}$ is larger than both $\mathrm{J}_{\text {inter16 } \times 8}$ and $\mathrm{J}_{\text {inter } 8 \times 16}$, we consider all sub-macroblock modes, as in the reference software.

\subsection{Complexity Reduction of Intra $4 \times 4$}

When $8 \times 8 \mathrm{DCT}$ is not used, the allowed intra modes are intra $4 \times 4$ and intra $16 \times 16$. Of the two intra modes, intra $4 \times 4$ has the higher complexity because it has more prediction modes. Since intra16 $\times 16$, as described in Section 2, has only four prediction modes and intra $4 \times 4$ has nine prediction modes for finer size, intra $4 \times 4$ generally yields smaller prediction error than intra $16 \times 16$.

However, most of the macroblocks have only small difference between the RD costs of intra $16 \times 16$ and intra $4 \times 4$. It is because edges directed in vertical or horizontal are dominant in natural images, which are considered in intra16x16.

Using this characteristic, we first find the inter mode with a minimum RD cost. Then we compare the RD cost of the selected inter mode with that of intra $16 \times 16$. If the RD cost of intra $16 \times 16$ is much larger, that is, Eq. (16) is satisfied, than the $\mathrm{RD}$ cost computation of intra $4 \times 4$ is skipped:

$$
\operatorname{Min}[\mathrm{RDcost}(\text { inter modes })] \cdot K<\mathrm{RD} \operatorname{cost}(\text { intra } 16 \times 16)
$$

In (16), $K$ is a constant. Table 1 describes the missing rate of intra $4 \times 4$. The missing rate indicates the probability that the skipped intra $4 \times 4$ has the smallest RD cost. As shown in Table 1, the average missing rate is only about $0.7 \%$ for $K=1.5$. This means that the RD cost difference between intra $4 \times 4$ and intra $16 \times 16$ is less than 1.5 times for $99.3 \%$ of the macroblocks.

\section{SIMULATION RESULTS}

Since the proposed methods for complexity reduction of inter $8 \times 8$ and intra $4 \times 4$ are uncorrelated, the two methods can be applied independently, or simultaneously. We applied the two proposed algorithms simultaneously to encode test sequences. For the purpose of evaluation, the public reference encoder JVT Model (JM) v.9.3 was used. The software was tested on an Intel Pentium-IV based computer with 512 MB RAM under the Windows XP Professional operating system.

TABLE 1. MISSING RATE OF INTRA $4 \times 4$ ACCORDING TO $K$
\begin{tabular}{|c|c|c|c|}
\hline \multirow{2}{*}{ Sequences } & \multicolumn{3}{|c|}{ Missing Rate $\mathbf{( \% )}$} \\
\cline { 2 - 4 } & $\boldsymbol{K}=\mathbf{1 . 3}$ & $\boldsymbol{K}=\mathbf{1 . 5}$ & $\boldsymbol{K}=\mathbf{1 . 7}$ \\
\hline Coastguard & 2.0 & 0.4 & 0.2 \\
\hline Container & 2.7 & 1.0 & 0.9 \\
\hline Mobile & 0.4 & 0.0 & 0.0 \\
\hline News & 5.8 & 0.6 & 0.5 \\
\hline Salesman & 6.6 & 0.4 & 0.0 \\
\hline Silent & 4.7 & 1.7 & 0.4 \\
\hline Stefan & 2.8 & 0.2 & 0.0 \\
\hline Trevor & 9.0 & 0.9 & 0.1 \\
\hline
\end{tabular}


TABLE 2. THE NUMBER OF RD COST COMPUTATIONS IN INTER $8 \times 8$.

\begin{tabular}{|c|c|c|c|}
\hline Sequences & $\begin{array}{c}\text { Reference } \\
\text { Software }\end{array}$ & $\begin{array}{c}\text { Proposed } \\
\text { Method }\end{array}$ & $\begin{array}{c}\text { Reduction } \\
\text { Ratio (\%) }\end{array}$ \\
\hline Coastguard & 156,816 & 59,760 & 62 \\
\hline Container & 156,816 & 17,896 & 89 \\
\hline Mobile & 156,816 & 65,360 & 58 \\
\hline News & 156,816 & 30,256 & 81 \\
\hline Salesman & 156,816 & 28,224 & 82 \\
\hline Silent & 156,816 & 40,464 & 74 \\
\hline Stefan & 156,816 & 56,472 & 64 \\
\hline Trevor & 156,816 & 54,800 & 65 \\
\hline
\end{tabular}

TABLE 3. THE NUMBER OF RD COST COMPUTATIONS IN INTRA $4 \times 4$.

\begin{tabular}{|c|c|c|c|}
\hline Sequences & $\begin{array}{c}\text { Reference } \\
\text { Software }\end{array}$ & $\begin{array}{c}\text { Proposed } \\
\text { Method }\end{array}$ & $\begin{array}{c}\text { Reduction } \\
\text { Ratio (\%) }\end{array}$ \\
\hline Coastguard & 35,343 & 10,838 & 69.3 \\
\hline Container & 35,343 & 6,566 & 81.4 \\
\hline Mobile & 35,343 & 400 & 98.9 \\
\hline News & 35,343 & 2,225 & 93.7 \\
\hline Salesman & 35,343 & 529 & 98.5 \\
\hline Silent & 35,343 & 2,388 & 93.2 \\
\hline Stefan & 35,343 & 3,038 & 91.4 \\
\hline Trevor & 35,343 & 3,463 & 90.2 \\
\hline
\end{tabular}

TABLE 4. COMPARISON OF BITRATES (Kbits).

\begin{tabular}{|c|c|c|c|}
\hline Sequences & $\begin{array}{c}\text { Reference } \\
\text { Software }\end{array}$ & $\begin{array}{c}\text { Proposed } \\
\text { Method }\end{array}$ & $\begin{array}{c}\text { Increase Ratio } \\
\text { (\%) }\end{array}$ \\
\hline Coastguard & 249.00 & 251.28 & 0.9 \\
\hline Container & 40.16 & 40.74 & 1.4 \\
\hline Mobile & 496.49 & 497.24 & 0.2 \\
\hline News & 75.84 & 76.75 & 1.2 \\
\hline Salesman & 56.89 & 57.61 & 1.3 \\
\hline Silent & 82.69 & 83.71 & 1.2 \\
\hline Stefan & 379.26 & 380.86 & 0.4 \\
\hline Trevor & 132.49 & 133.58 & 0.8 \\
\hline
\end{tabular}

TABLE 5. COMPARISON OF PSNRS.

\begin{tabular}{|c|c|c|c|}
\hline Sequences & $\begin{array}{c}\text { Reference } \\
\text { Software (dB) }\end{array}$ & $\begin{array}{c}\text { Proposed } \\
\text { Method (dB) }\end{array}$ & $\begin{array}{c}\text { Difference } \\
\text { (dB) }\end{array}$ \\
\hline Coastguard & 33.93 & 33.89 & 0.04 \\
\hline Container & 36.07 & 36.06 & 0.01 \\
\hline Mobile & 33.14 & 33.06 & 0.08 \\
\hline News & 36.65 & 36.64 & 0.01 \\
\hline Salesman & 35.57 & 35.54 & 0.03 \\
\hline Silent & 35.84 & 35.81 & 0.03 \\
\hline Stefan & 34.22 & 34.15 & 0.07 \\
\hline Trevor & 36.40 & 36.33 & 0.07 \\
\hline
\end{tabular}

We adopted full search for ME, used RDO, and set Quantization Parameter (QP) and K in (16) to 28 and 1.5, respectively. The simulation was performed on eight standard video sequences in QCIF (176x144) format. These included Coastguard, Container, Mobile, News, Salesman, Silent, Stefan, and Trevor. These sequences were selected on the basis of length of encoded streams and degree of motion. The first 100 frames of each of these sequences were used.

For 99 frames, Tables 2 and 3 describe the reduction ratios of the number of $\mathrm{RD}$ cost computations in inter8x8 and intra $4 \times 4$. As shown in these results, we can save about $72 \%, 90 \%$ of the RD cost computations, respectively.

Tables 4 and 5 compare the bitrates and PSNRs for each test sequence. Since the reference implementation is an exhaustive search for selecting the macroblock mode, the

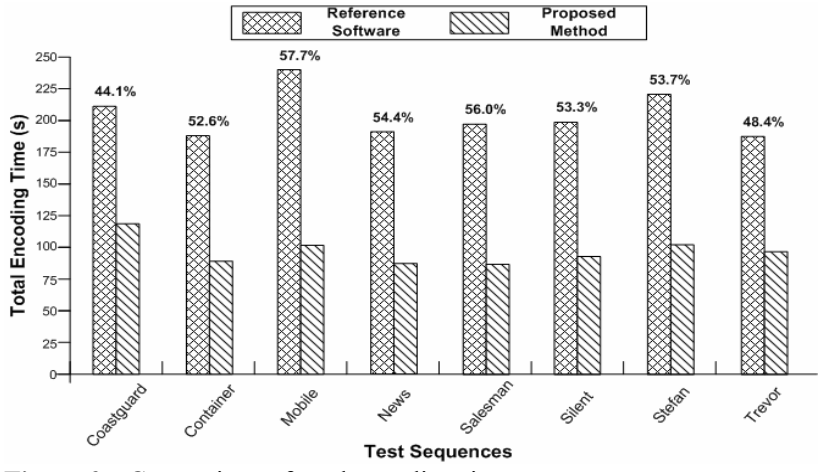

Figure 3. Comparison of total encoding time

number of encoded bits is the least for each sequence. Tables 4 and 5 show the average increase of the total bitrates is only about $0.9 \%$, and the average PSNR drop is only about $0.043 \mathrm{~dB}$ when using the proposed method.

Finally, Fig. 3 compares total encoding time from the proposed method with that from the reference software. This result shows substantial decrease of about $53 \%$ in total encoding time compared with the reference implementation.

\section{CONCLUSION}

We proposed two simple and effective schemes for quick selection of macroblock modes in H.264 video coding. Using our methods, the RD cost computations of inter $8 \times 8$ and intra $4 \times 4$ was reduced about $72 \%$ and $90 \%$, respectively. Both schemes can be applied independently. When both methods are used simultaneously, simulation results show that our methods can save about $53 \%$ of total encoding time regardless of input sequences, yet the average increased rate of the total bits and average PSNR drop are only about $0.9 \%$ and $0.043 \mathrm{~dB}$, respectively. This huge reduction of encoder complexity may be useful in real-time implementation of the H.264/AVC standard.

\section{REFERENCES}

[1] JVT K051, "Version 3 of H.264/AVC (ITU-T Rec. H.264/ISO/IEC 14496-10 AVC)," July 2004.

[2] T. Wiegand and G. J. Sullivan, "Overview of the H.264/AVC Video Coding Standard," IEEE Trans. Circuits Syst. Video Technol., vol. 13, pp. 560-576, July 2003.

[3] T. Wiegand, H. Schwarz, A. Joch, and F. Kossentini, "RateConstrained Coder Control and Comparison of Video Coding Standard," IEEE Trans. Circuits Syst. Video Technol., vol. 13, pp. 688-703, July 2003.

[4] P. Yin, H. C. Tourapis, A. M. Tourapis, and J. Boyce, "Fast Mode Decision and Motion Estimation for JVT/H.264," ICIP'03, vol. 3, pp. 853-856, Sept. 2003.

[5] Y. W. Huang, B. Y. Hsieh, T. C. Whang, S. Y. Chien, S. Y. Ma, C. F. Shen, and L. G. Chen, "Analysis and Reduction of Reference Frames for Motion Estimation in MPEG-4 AVC/JVT/H.264," ICASSP'03, vol. 3 pp. 145-148, April 2003.

[6] A. Ahmad, N. Khan, S. Masud, and M.A. Maud, "Efficient block size selection in H.264 video coding standard," Electronics Letters, vol. 40, pp. 19-21, Jan. 2004.

[7] JM9.3: http://bs.hhi.de/ suehring/tml/ download/ jm93.zip. 